\title{
REKREASYONEL MOTIVASYON VE TATMIN
}

\author{
Editör
}

Süleyman Erim ERHAN

Yazar

Fatih AĞDUMAN 


\section{(C) Copyright 2020}

Bu kitabın, basım, yayın ve satış haklar Akademisyen Kitabevi A.Ş.'ne aittir. Anılan kuruluşun izni alınmadan kitabın tümü ya da Bölümleri mekanik, elektronik, fotokopi, manyetik kağıt ve/veya başka yöntemlerle çoğaltılamaz, basılamaz, dağıtılamaz. Tablo, şekil ve grafikler izin alınmadan, ticari amaçh kullanılamaz. Bu kitap T.C. Kültür Bakanlığ bandrolü ile satılmaktadır.

Doç. Dr. Süleyman Erim ERHAN danışmanlığında 2014 Yılında Atatürk Üniversitesi Sağlık Bilimleri Enstitüsü, Beden Eğitimi ve Spor Anabilim Dalı öğrencisi Fatih AĞDUMAN tarafından kitap olarak yayımlanan bu çalışma "Üniversite Öğrencilerinin Boş Zaman Motivasyon ve Tatmin Düzeylerinin İncelenmesi” başlıklı Yüksek Lisans tezinden üretilmiştir.

\section{ISBN}

978-625-7707-72-5

Kitap Ad1

Rekreasyonel Motivasyon ve Tatmin

\section{Editör}

Süleyman Erim ERHAN

ORCID iD: 0000-0003-4437-0807

Yazar

Fatih AĞDUMAN

ORCID iD: 0000-0002-5744-7191

Yayın Koordinatörü

Yasin Dilmen

Sayfa ve Kapak Tasarımı

Akademisyen Dizgi Ünitesi

Yayıncı Sertifika No

47518

Baskı ve Cilt

Vadi Matbaacılık

Bisac Code

BUS046000

\section{GENEL DAĞITIM Akademisyen Kitabevi A.Ş.}

Halk Sokak 5 / A

Yenişehir / Ankara

Tel: 03124311633

siparis@akademisyen.com

\section{www. a ka demisyen.com}




\section{ÖNSÖZ}

Özellikle 20. Yüzyılda önemi daha da artan bireylerin rekreasyonel motivasyon ve tatmin kavramları ile ilgili yapılan bu araştırmadaki amaç, Atatürk Üniversitesi Öğrencilerinin Boş Zaman Motivasyon ve Tatminlerinin farklı değişkenlerle karşılaştırılarak aralarındaki ilişkinin incelenmesidir. Araştırma, tabakalı örnekleme yöntemi kullanılarak uygulanmıştır. Üç bölümden meydana gelen anket formatında bilgi toplama aracı kullanılan çalışmaya 218 kadın ve 244 erkek olmak üzere toplam 462 öğrenci katılmıştır. İlk bölümde demografik özelliklerle alâkalı maddeler, ikinci bölümde 2008 senesinde Mutlu’nun Türkçeye uyarladığı "Boş Zaman Motivasyon Ölçeği”, üçüncü bölümde ise Karlı tarafından Türkçeye uyarlanan "Serbest Zaman Tatmin Ölçeği” kullanılarak çeşitli istatistiki analizler uygulanmıştır. Yapılan araştırmada öğrencilerin boş zaman motivasyonları ile tatminleri arasında p $<0.01$ düzeyinde anlamlı ilişki bulunmuştur. Araştırmada katılımcıların boş zaman motivasyon alt boyutlarından bilmek ve başarmak, uyaran yaşama ve özdeşim/içe atım ortalamasıyla boş zaman aktivitelerinden tatmin olma toplam puanı arasında istatistiki olarak anlamlı düzeyde $(\mathrm{p}<0.01)$ ilişki bulunmuştur. Ayrıca güdülenmemeyle diğer alt boyutlar ve boş zaman toplam tatmin puanı arasında da istatistiki olarak anlamlı düzeyde bir ilişki bulunmuştur $(\mathrm{p}<0.01)$. 


\section{IÇERIKLER}

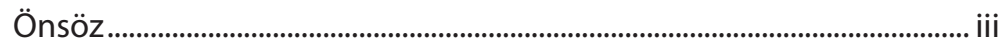

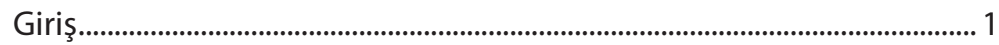

\section{BíRINCI BÖLÜM \\ ZAMAN, BOŞ ZAMAN VE REKREASYON KAVRAMLARI VE ÖZELLIKLLRi}

1.1. Zaman Kavramı ...................................................................................... 3

1.2. Boş Zaman Kavramı .................................................................................... 5

1.2.1. Boş Zaman....................................................................................... 5

1.2.2. Boş Zamanın Temel Fonksiyonları ................................................ 8

1.2.2.1. Dinlenme Fonksiyonu...................................................... 9

1.2.2.2. Eğlenme Fonksiyonu......................................................... 9

1.2.2.3. Gelişim Fonksiyonu ............................................................. 9

1.2.3. Boş Zamanları Değerlendirmenin Yararları.............................10

1.2.3.1. Fiziksel Yararlar .................................................................10

1.2.3.2. Psikolojik Yararlar................................................................11

1.2.3.3. Toplumsal Yararları............................................................11

1.3. Rekreasyon Kavramı .........................................................................12

1.3.1. Rekreasyonun Özellikleri ..............................................................15

1.3.2. Rekreasyonun Sınıflandırılması .................................................16

1.3.3. Rekreasyonun Yararları ...................................................................19

\section{İKiNCi BÖLÜM \\ MOTIVASYON VE TATMIN KAVRAMLARI}

2.1. Motivasyon Kavramı................................................................................ 21

2.1.1. Motivasyonla İlgili Temel Kavramlar .........................................22

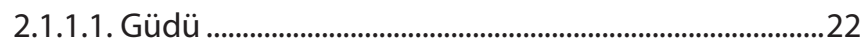

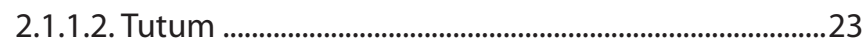

2.1.1.3. Davranış ................................................................................ 23 
vi $\mid$ İçindekiler

2.1.2. Maslow'un İhtiyaçlar Hiyerarşisi...............................................24

2.1.3. Motivasyon Türleri.........................................................................22

2.1.3.1. İçsel Motivasyon ..................................................................2

2.1.3.2. Dışsal Motivasyon ............................................................29

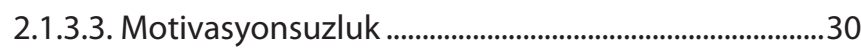

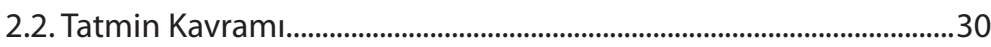

\section{ÜÇÜNCÜ BÖLÜM \\ REKREASYONEL MOTIVASYON VE TATMIN ILE ILGILI \\ ALAN ARAŞTIRMASI}

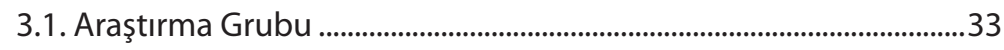

3.2. Veri Toplama Araçları - Veri Analizi ........................................................33

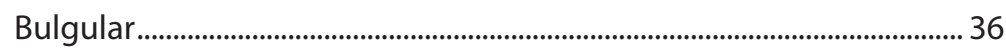

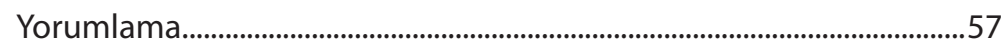

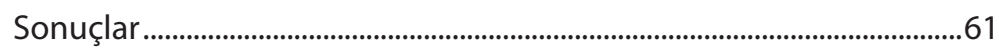

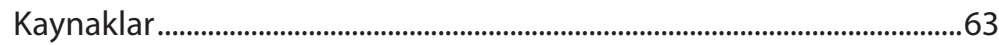




\section{KAYNAKLAR}

1. Türk Dil Kurumu Türkçe Sözlük, Ankara, TDK Yayını, 1982: 884.

2. Doğan İ, Sosyoloji: Kavramlar ve Sorunlar, 5. Baskı. Ankara, Pegem Akademi Yayıncilık, 2002.

3. Henderson KA, Bialeschki DM, Shaw SM, Freysinger VJ. Both gains and gaps: feminist perspectives on women's leisure. State College: Venture Publising, 1996.

4. Karaküçük S. Rekreasyon - Boş Zaman Değerlendirme, 5.Basım. Ankara, Gazi Kitapevi, 2005: 3-59-89.

5. Kleiber D. Leisure Experience and Human Development: A Dialectical Interpretation, New York, Basic Behavioral Science, 1999.

6. Tezcan M. Boş Zamanların Değerlendirilmesi Sosyolojisi 4. Baskı. Ankara, Atilla Kitabevi, 1994.

7. Lynch R, Veal AJ. Australian Leisure, South Melbourne, Addison Wesley Longman, 1996.

8. Abadan N. Türk Üniversite Öğrencilerinin Serbest Zaman Faaliyeti. Boş Zamanları Değerlendirme Semineri. İstanbul: Halk Sağlığı Eğitim Komitesi Yayını; 1966.

9. Erbesler A. İşgücünün Zaman Kullanımı ve Isş Verimliliğini Etkileyen Sosyo-Ekonomik Faktörler, Ankara, Milli Prodüktivite Merkezi Yayınları, 1987.

10. Baud-Bovy M, Lawson F. Tourism and Recreation: Handbook of Planning and Design, Oxford, Architectural Press, 1998.

11. Gökçe B. Orta Öğretim Gençliğinin Beklenti ve Sorunları, Ankara, Milli Eğitim Bakanlığı Yayını, 1984.

12. Güler Ş. Turizm Sosyolojisi, Ankara, Turizm ve Tanıtma Bakanlığ 1 Yayını, 1978.

13. Leighfield M. 2001 Yilında boş zaman: boş zaman toplumu için bilgi. Çeviren: Demiray U. Aylık Turizm ve Kültür-Sanat Dergisi, 1990, 1:7-10. 
14. Suiçmez H. Türkiye Ve İngiltere'deki Sportif Rekreasyon Yöneticilerinin Karakteristik Özellikleri. Sağlık Bilimleri Enstitüsü. Doktora Tezi, Trabzon: Karadeniz Teknik Üniversitesi, 2000.

15. Coleman R, Barrie G. Manager's Guide. Çeviri: Harmancı M. Yöneticinin Kılavuzu, İstanbul, Remzi Kitabevi, 2000.

16. Kovacs A. The Leisure Personality: Relationships Between Personality, Leisure Satisfaction, and Life Satisfaction. School of Health, Physical Education and Recreation. Doktora Tezi, Indiana: Indiana University, 2007.

17. Mannell RC, Kleiber DA. A Social Psychology of Leisure, Venture Publishing, 1997.

18. Karlı Ü, Polat E, Yılmaz B, Koçak S. Serbest zaman tatmin ölçeğinin (SZTÖ-Uzun versiyon) geçerlilik ve güvenilirlik çalışması, Hacettepe Spor Bilimleri Dergisi, 2008, 19: 80-91.

19. Hou J, Tu HH, Yang M. Agreeableness and leisure satisfaction in the context of online games. Social Behavior and Personality, 2007, 35:1379-1384.

20. Tu HH, Chen LS, Wang MC, Lin JY. The impact of neuroticism on leisure satisfaction: Online game application, Social Behavior and Personality, 2007, 35:1399-1404.

21. Beggs BA, Elkins DJ. The influence of leisure motivation on leisure satisfaction, The Cyber Journal of Applied Leisure and Recreation Research, 2010.

22. Chen YC, Li RH, Chen SH. Relationships among adolescents' leisure motivation, leisure involvement and leisure satisfaction: A structural equation model, Social Indicators Research, 2013, 110:1187-1199.

23. Kao C. A Model of Leisure Satisfaction. School of Health, Physical Education and Recreation. Doktora Tezi, Indiana: Indiana University, 1992.

24. Huang C, Carleton B. The relationships among leisure participation, leisure satisfaction, and life satisfaction of college students in Taiwan, Journal of Exercise Science and Fitness, 2003, 1:129-132. 
25. Trottier AN, Brown GT, Hobson SJG, Miller W. Reliability and validity of the Leisure Satisfaction Scale (LSS-short form) and the Adolescent Leisure Interest Profile (ALIP), Occupational Therapy International, 2002, 9:131-144.

26. Harden MD. The Five Factor Model of Personality and Leisure Experience. Yüksek Lisans Tezi, Fullerton: California State University, 2008.

27. Ngai VT. Leisure satisfaction and quality of life in Macao, China, Leisure Studies, 2005, 24(2):195-207.

28. Ana Britannica Genel Kültür Ansiklopedisi, İstanbul, Ana Yayınevi, 2000.

29. Karaküçük S. Rekreasyon, Boş Zamanları Değerlendirme, 2.Bask1. Ankara, Bağırgan Yayınevi, 1997.

30. Jones K. Zamanı Kullanma: Kendi Kendini Geliştirme Programı, Çeviren: Akkoyunlu AC. İstanbul, Doğan Kitapçılık, 2000.

31. Karaküçük S, Ekenci G. Okulların Boş Zamanları Değerlendirme (Rekreasyon) Eğitimindeki Rolü, Milli Eğitim Dergisi, 1995, 128: 62-66.

32. Abadan N. Üniversite Öğrencilerinin Serbest Zaman Faaliyetleri, Ankara, Ankara Üniversitesi Siyasal Bilgiler Fakültesi Yayınları, 1961.

33. Gökmen H, Açıkalın A, Koyuncu N, Saydar Z. Yüksek Öğrenim Öğrencilerinin Serbest Zaman Etkinlikleri, Kendilerini Gerçekleştirme Düzeyleri, Ankara, Milli Eğitim Gençlik ve Spor Bakanlığı Gençlik Hizmetleri ve Faaliyetleri Dairesi Başkanlığı Yayınları, 1985.

34. Jensen CR. Outdoor Recreation in America, 5th Edition. USA, Human Kinetics, 1995.

35. Doğruyol A. Türk-İslam Sentezi Üzerine İncelemeler, Amsterdam Postast.

36. Aytaç Ö. Modern toplumda boş zaman olgusu. Dünya'da ve Türkiye'de Sosyolojik Gelişmeler, I. Baskı. Ankara, Sosyoloji Derneği Yayınları, 1997: 341-356. 
37. Bodur F. Anadolu Üniversitesi İktisadi ve İdari Bilimler Fakültesi Öğrencilerinin Boş Zamanlarını Değerlendirme Eğilimleri. Sosyal Bilimler Enstitüsü. Yüksek Lisans Tezi, Eskişehir: Anadolu Üniversitesi, 1988.

38. Arslan S. Yükseköğrenim Kredi ve Yurtlar Kurumuna Bağl1 Yurtlarda Kalan Bayan Öğrencilerin Rekreasyon Sorunları Üzerine Bir Araştırma. Sağlık Bilimleri Enstitüsü, Beden Eğitimi ve Spor Anabilim Dalı. Yüksek Lisans Tezi, Ankara: Gazi Üniversitesi, 1996.

39. Bayraktar C. Sosyal yapı özelliklerinin spora etkisi. Uludă̆ Üniversitesi Eğitim Fakültesi Dergisi, 2003, 17(1):19-36.

40. Cordes KA, İbrahim HM. Applications in Recreation \& Leisure: For Today and Future, 2nd Edition. Boston, McGraw-Hill Companies, 1999.

41. Şahin HM. Beden Eğitimi ve Spor Sözlüğü, İstanbul, Morpa Kültür Yayınları, 2005.

42. Broadhurst R. Managing Environments for Leisure and Recreation, 1st Edition. London, Routledge, 2001.

43. Bucher CH, Bucher CA. Recreation For Today's Society, New Jersey, 1974: 1-7.

44. Davis RJ, Bull CR, Roscoe JV, Rocoe DA. Physical Education and The Study of Sport, England, Wolf Publishing, 1991: 355.

45. Sağcan M. Rekreasyon ve Turizm, İzmir, Cumhuriyet Baskı Evi, 1986: 5.

46. Püsküllüoğlu A. Türkçe Sözlük, 10.Baskı. Ankara, Türk Dil Kurumu Yayınları, 2005.

47. Güngörmüş HA. Özel Sağllk-Spor Merkezlerinden Hizmet Alan Bireyleri Rekreasyonel Egzersize Güdüleyen Faktörler. Sağllk Bilimleri Enstitüsü, Beden Eğitimi ve Spor Anabilim Dalı. Doktora Tezi, Ankara: Gazi Üniversitesi, 2007.

48. Horner S, Swarbrooke J. Leisure Marketing: A Global Perspective (Paperback), 1st Edition. Oxford, Elsevier Butterworth-Heinemann, 2005. 
49. Koçer HA. Eğitim Tarihi, Ankara, Ankara Üniversitesi Yayını, 1977.

50. Curtis JE. Recreation Theory and Pracilce, Toronto, Mosby Company, 1979.

51. Ağaoğlu Y. S. Türkiye'deki Üniversitelerin Rekreasyon Programlar1nın Geliştirilmesi. Sağllk Bilimleri Enstitüsü, Beden Eğitimi ve Spor Anabilim Dalı. Doktora Tezi, Samsun: Ondokuz Mayıs Üniversitesi, 2002.

52. Zülal A. Sağlık için hareket edin. Bilim ve Teknik Dergisi, 2002, Ağustos:72-75.

53. Zorba E, Kartal R. Sağlığımız ve Egzersiz, 2000: 7-10.

54. Erkal M. Sosyolojik Açıdan Spor, İstanbul, Filiz Kitapevi, 1982: 10.

55. Erdemli A. Temel Sorunlartyla Spor Felsefesi, İstanbul, E Yayınları, 2002: 31 .

56. Yörükoğlu A. Çocuk Ruh Sağllğı, 3.Baskı. Ankara, TGB Kültür, 1980: 5 .

57. Karaküçük S. Rekreasyon Boş Zamanları Değerlendirme, 3.Basım. Ankara, Gazi Kitabevi, 1999: 6-85-128.

58. Kılbaş Ş. Gençlik ve Boş Zamanı Değerlendirme, Adana, Çukurova Ün. Basımevi, 1994: 41.

59. Tezcan M. “Hobi (Hobby) nedir?”. Bilim ve Teknik Dergisi, 1977, 111: 31.

60. Soyer F, Can Y. Üniversite öğrencilerinin boş zaman alışkanlıkları ve sportif eğilimlerinin mesleki yönelişlerine göre karşılaştırılması. $I$. Gençlik Boş Zaman ve Doğa Sporları Sempozyumu, 2003: 102-120.

61. Karaküçük S. Rekreasyon Boş Zamanları Değerlendirme, 4.Baskı. Ankara, Gazi Kitabevi, 2001: 56-57.

62. Demiray U. Açıköğretim Fakültesi Öğrencilerinin Boş Zamanlarını Değerlendirme Eğilimleri, Eskişehir, Anadolu Üniversitesi Yayını, 1987.

63. Bozatay H. Devlet Memurlarının Rekreatif Faaliyetleri Üzerine Bir Araştırma (Çanakkale İli Uygulaması). Sosyal Bilimler Enstitüsü, Beden Eğitimi ve Spor Anabilim Dalı. Yüksek Lisans Tezi, Sakarya: Sakarya Üniversitesi, 1998. 
64. Yazıcı M. Üniversite Öğrencilerinin Boş Zamanlarını Değerlendirme Anlayış ve Alışkanlıkları Üzerine Kapsamlı Bir Araştırma (Atatürk Üniversitesi Örneği). Sağlık Bilimleri Enstitüsü. Yüksek Lisans Tezi, İstanbul: Marmara Üniversitesi, 1998.

65. Leither MJ, Leitner SF. Leisure Enhancement, London, The Haworth Press, 2004.

66. Çakıroglu H. Beden Eğitimi Dersi ve diğer Dersler Açısından Okullarda Ders Dışı Faaliyetlerin Durumu Eğitsel Kollar ve Faaliyetleri. Sağlık Bilimleri Enstitüsü, Beden Eğitimi ve Spor Anabilim Dalı. Yüksek Lisans Tezi, İstanbul: Marmara Üniversitesi, 1998.

67. Kılbaş Ş. Rekreasyon, 3. Baskı. Ankara, Nobel Yayınları, 2004.

68. Önal A. Ev Hanımlarının Rekreasyon Faaliyetlerine Katılımlarının Ve Beklentilerinin Tespiti. Sosyal Bilimler Enstitüsü, Beden Eğitimi ve Spor Anabilim Dalı. Yüksek Lisans Tezi, Sakarya: Sakarya Üniversitesi, 2007.

69. Fidan N. Okulda Ögrenme ve Ögretme, İstanbul, Beta Basımevi, 1997.

70. Biçer T. Sporda Duygu ve Aklın Yönetimi, 1.Baskı. İstanbul, Beyaz Yayınları, 2007.

71. Kim HS. Kendinizi ve Başkalarını Motive Etmenin 1001 Yolu, Çeviri: Çimen A. İstanbul, Timaş Yayınları, 2005.

72. Arık İA. Motivasyon ve Heyecana Giriş, İstanbul, Çantay Kitabevi, 1996.

73. Dörnyei Z. Teaching and Researching Motivation, Essex, Longman, 2001.

74. Wu X. Intrinsic motivation and young language learners: the impact of the class. 20. Room Environment, 2003, 31:501-517.

75. Selçuk Z, Eğitim Psikolojisi, Ankara, Pegem Akademi, 1996.

76. Baysal AC, Tekerarslan E. İşletmeler İçin Davranış Bilimleri, İstanbul, Avcıol Basım-Yayın, 1996.

77. Karabacak E. Medyanın Tüketici Davranışları Üzerindeki Etkisi ve Pazarlama Yönetimi Açısından Önemi. Sosyal Bilimler Enstitüsü, ik- 
tisat Anabilim Dalı. Yüksek Lisans Tezi, Konya: Selçuk Üniversitesi, 1993.

78. Erden M, Akman Y. Gelişim ve Öğrenme, Ankara, Arkadaş Yayınevi, 2002: 264.

79. Özgener S. Organizasyonlarda iş ahlakının kurumsallaşması. http:// www.stratejiyonetim.net/isahlaki.htm 31 Temmuz 2007.

80. Özkalp E. Örgütsel Davranış, Eskişehir, Anadolu Üniversitesi Yayınları, 1999.

81. Özmenteş G. Müzik dersine yönelik tutum ölçeğinin geliştirilmesi. http://www.ilkogretim-online.org.tr 4 Nisan 2006.

82. Eren E. Örgütsel Davranış ve Örgüt Psikolojisi, 5. Baskı. İstanbul, Beta Yayınları, 1998.

83. Şimşek M, Akgemci T, Çelik A. Davranış Bilimlerine Giriş ve Örgütlerde Davranış, Ankara, Nobel Yayım Dağıtım, 1998.

84. Eroğlu F. Davranış Bilimleri, 5. Baskı. İstanbul, Beta Basım, 2000.

85. Özalp E, Kirel Ç. Örgütsel Davranış, Eskişehir, Etan Matbaası, 1996.

86. Woolfolk AE. Educational Psychology. Sixth Edition. USA, Allyn and Bacon. A. Simon and Schuster Company, 1995.

87. Soyer F. Üniversite Öğrencilerinin Boş Zaman Alışkanlıkları ve Sportif Eğilimlerinin Mesleki Yönelişlerine Göre Karşılaştırılması. Sağlık Bilimleri Enstitüsü. Yüksek Lisans Tezi, Kayseri: Erciyes Üniversitesi, 1997.

88. Feldman RS. Understanding Psychology, Fourth Edition. McGraw-Hill, Inc, 1996.

89. Hoy WK, Miskel CG. Education Management. Çeviri: Turan S. Ĕgitim Yönetimi, Ankara, Nobel Yayıncılık, 2010.

90. Plotnik R, Haig K. Introduction to Psychology, 8th Edition. Belmont, Thomson Learning Inc, 2008.

91. Stipek, D. Motivation To Learn: From Theory To Practice, Third Edition. Massachusetts, A Viacom Company, 1998.

92. Shinn G. Motivasyonun Mucizesi, 1. Baskı. İstanbul, Sistem Yayıncilik, 1996. 
93. Genç N. Motivasyonun Önemi ve Genel Olarak Motivasyon Teorileri, Sosyal Bilimler Enstitüsü. Yüksek lisans Tezi, Erzurum: Atatürk Üniversitesi, 1987.

94. Ulusoy A. Gelişim ve Öğrenme, 2. Baskı. Ankara, Arı Yayıncılık, 2003.

95. Selçuk Z. Gelişim ve Öğrenme, 9. Baskı. Ankara, Nobel Yayınları, 2003.

96. Ülgen G. Eğitim Psikolojisi, 3. Baskı. İstanbul, Alkım Yayınevi, 1997.

97. Vallerand RJ, Pelletier LG, Blais MR, Briere NM, Senecal C, Valleres EF. The

1. academic motivation scale: a measure of intrinsic, extrinsic and amotivation in education. Educational and Psychological Measurement, 1992, 52.

98. Abacı R. Yaşamın Kalitelendirilmesi, İstanbul, Sistem Yayıncılık, 2000: 87.

99. Özdevecioğlu M, Yalçın Y. Spor tatmininin sporcuların stres ve saldırganlık düzeyleri üzerindeki etkisi. Niğde Üniversitesi Besyo Dergisi, 2010, 4 (1):63-76.

100. Eroğlu F. Davranış Bilimleri, 10.Baskı. İstanbul, Beta Basım Yayım Dağıtım, 2004.

101. Tsai YM. The Study of Exercise Participation Motivation, Self-Efficacy, Perceived Exercise Barrier and Exercise Behavior. Master's Thesis. Taichung: National Chung Hsing University, 2005.

102. Gökçe H. Serbest Zaman Doyumunun Yaşam Doyumu ve Sosyo Demografik Değişkenlerle İlişskisinin İncelenmesi. Sağlık Bilimleri Enstitüsü, Sporda Psiko-Sosyal Alanlar Anabilim Dalı. Yüksek Lisans Tezi, Denizli: Pamukkale Üniversitesi, 2008.

103. Kaya AM. Üniversite Öğrencilerinin Rekreatif Faaliyetlere Yönelik Tutumları ve Boş Zaman Motivasyonlarının Bazı Değişkenler Açısından İncelenmesi. Sağlık Bilimleri Enstitüsü, Beden Eğitimi ve Spor Anabilim Dalı. Yüksek Lisans Tezi, Sivas: Cumhuriyet Üniversitesi, 2011. 
104. Francken DA, Raaij F. Satisfaction with leisure time activities. Journal of Leisure Research, 1981, 13:337-352.

105. Mutlu İ, Yılmaz B, Güngörmüş HA, Sevindi T, Gürbüz B. Bireyleri rekreasyonel amaçlı egzersize motive eden faktörlerin çeşitli değişkenlere göre karşılaştırılması. Selçuk Üniversitesi Beden Eğitimi ve Spor Bilim Dergisi, 2011, 13: 54-61.

106. Büküşoğlu N, Bayturan AF. Serbest zaman etkinliklerinin gençlerin psiko-sosyal durumlarına ilişkin algısı üzerindeki rolü. Ege Tıp Dergisi, 2005, 44: 173-177.

107. Hsieh CM. Leisure Attitudes, Motivation, Participation and Satisfaction: Test of a Model of Leisure Behavior. School of Health, Physical Education and Recreation. Doktora Tezi, Indiana: Indiana University, 1998. 